\title{
Single-digit cold-induced vasodilation adaptations during an Antarctic expedition
}

\author{
Christopher James Tyler ${ }^{1} \cdot$ Robert Lambert $^{2} \cdot$ Alexander Kumar $^{3} \cdot$ Mike Adrian Stroud $^{4} \cdot$ Stephen Sau-Shing Cheung ${ }^{5}$
}

Received: 11 April 2019 / Revised: 23 March 2020 / Accepted: 25 March 2020 / Published online: 1 April 2020

(c) The Author(s) 2020

\begin{abstract}
An increasing number of people are spending time in Polar Regions for work and tourism and this can increase the risk of tissue injuries, e.g. frostbite. The risk would be reduced if beneficial peripheral blood flow adaptions occurred but data regarding the trainability of the cold-induced vasodilation (CIVD) response are equivocal. Five healthy males spent almost 8 months in Antarctica; five of them at a semi-permanent camp $\left(-44^{\circ} \mathrm{C} ; 2752 \mathrm{~m}\right)$. CIVD tests ( $30 \mathrm{~min}$ index finger immersion into $0{ }^{\circ} \mathrm{C}$ water) were performed on the 12th, 39-40th, 67-68th, 179th and 234th days of the expedition in a climate-controlled caboose. Heart rate (HR), thermal sensation of the finger, pain sensation, and mean arterial pressure (MAP) were recorded. Minimum, maximum, and mean finger temperature were greater, onset time was earlier $(r=0.34)$, and amplitude was greater $(r=0.55)$ on day 234 than day 12 suggesting that adaptation occurred. Time-point data suggested that the adaptations were progressive. Cardiovascular and perceptual data also showed some adaptation. MAP was lower on day 234 than day 12 $(r=0.47$ and $r=0.47)$ but mean HR was higher $(r=0.55)$. Mean and peak thermal sensation $(r=0.31-0.59 ; r=0.31)$ and perceived pain $(r=0.58 ; r=0.36)$ both improved over the course of the expedition. Of interest to Polar Region visitors, beneficial peripheral and perceptual adaptations to prolonged Antarctic exposure can occur with $2 \mathrm{~h}$ of daily outdoor exposure although the rates at which adaptation occurs differ.
\end{abstract}

Keywords CIVD $\cdot$ Antarctica $\cdot$ Hunting-response $\cdot$ Cold exposure $\cdot$ Cold injury $\cdot$ Skin temperature

Christopher James Tyler

chris.tyler@roehampton.ac.uk

Robert Lambert

robbie_lambert@hotmail.com

Alexander Kumar

dralexanderkumar@gmail.com

Mike Adrian Stroud

M.A.Stroud@soton.ac.uk

Stephen Sau-Shing Cheung scheung@brocku.ca

1 Department of Life Sciences, University of Roehampton, London SW15 4JD, England, UK

2 Department of Orthopaedic Surgery, Royal Infirmary of Edinburgh, Little France Crescent, Edinburgh EH16 4SA, Scotland, UK

3 Department of Physiologie, University of Fribourg, 1700 Fribourg, Switzerland

4 National Institute for Health and Research, Biomedical Research Centre in Nutrition, Southampton University Hospital Trust, Southampton SO16, 6YD, England, UK

5 Department of Kinesiology, Brock University, Saint Catharines, ON, Canada

\section{Introduction}

Exposure to cold environmental temperatures induces a sympathetically mediated vasoconstriction of the peripheral blood vessels which decreases whole-body heat loss at the potential expense of local freezing (Ward 1974) and non-freezing (Imray et al. 2011) cold injuries. After approximately 10-15 min of continued cold exposure, this reduction in peripheral blood flow is often followed by a cyclical increase and decrease in skin blood flow and skin temperature, commonly termed cold-induced vasodilation (CIVD) (Lewis 1930; Daanen 2003; Cheung and Daanen 2012), which may offer protection against cold injuries (Daanen and van der Struijs 2005).

Individuals who live in polar regions appear to have an enhanced CIVD response and cold tolerance compared to those that do not (Krog et al. 1960; Miller and Irving 1962; Purkayastha et al. 1992), suggesting that localised adaptation to cold temperatures may occur. Laboratory data have shown that the CIVD response may be impaired (Mekjavic et al. 2008; Daanen et al. 2012), unaffected (Geurts et al. 2006), 
or improved (Adams and Smith 1962; Geurts et al. 2005), by repeated immersions of the whole hand or fingers in cold water, and similarly equivocal data have been reported following Arctic and Antarctic expeditions. Ten months of residency in Antarctica had no effect on the time of CIVD onset, the blood flow at onset, or the frequency of CIVD cycles but decreased the amplitude of the CIVD response in noncold-habituated participants (Elkington 1968). In another study, 12 months in Antarctica actually reduced finger temperatures when exposed to $5{ }^{\circ} \mathrm{C}$ air (Wyndham et al. 1964). Mixed data have been reported following 2 weeks in the Arctic with potentially negative [lower mean finger temperature, lower CIVD onset temperature and later CIVD onset time (Livingstone 1976)] and potentially positive [increased finger blood flow (Naidu and Sachdeva 1993) and increased finger temperatures (Purkayastha et al. 1992; Rintämäki et al. 1993)] adaptations having been reported. Eight weeks of Arctic exposure was sufficient for individuals who usually reside in the tropics to have similar CIVD and peripheral blood flow responses (Purkayastha et al. 1992) to those usually living in the Arctic region suggesting that short-term exposure can be sufficient to offset long-term adaptation benefits and that adaptation to the cold is possible.

Unlike in the Arctic, during Antarctic expeditions, humans face both extreme cold and altitude (mean annual ambient temperature: approximately $-50{ }^{\circ} \mathrm{C}$; mean elevation: approximately $2500 \mathrm{~m}$ ); however, until recently, the cold-induced adaptations made to these combined stressors had not been investigated (Keramidas et al. 2018). Acute exposure to altitude $(3500 \mathrm{~m})$ can transiently reduce the CIVD response in lowland natives (Mathew et al. 1977; Daanen and van Ruiten 2000); however, normobaric hypoxia has no effect unless coupled with regular exercise (Keramidas et al. 2015) and hypobaric hypoxia has no effect in normal ambient temperatures (O'Brien et al. 2015). Whilst the data regarding the effects of acute altitude exposure of CIVD responses are equivocal, responses can be improved following long-term exposure. Participants acclimatised to 5100-7000 $\mathrm{m}$ for 45 days had a stronger CIVD response than subjects who had only spent 3 days exposed to an altitude of 5100 m (Daanen and van Ruiten 2000) and similar responses have been observed after 21 (Felicijan et al. 2008 ) and 28 (Amon et al. 2012) days of hypoxia. Recently, Keramidas et al. (2018) investigated the effects of cold and hypoxia on central and local adaptations to the cold during an 11-day man-hauling expedition on the South Polar Plateau and observed that peripheral blood flow adaptations can occur but the main adaptation appears to be a suppression of shivering thermogenesis.

To date, the effects of altitude on the CIVD response has largely been ignored in previous Antarctic field studies, with measurements often taken at unrecorded elevations (Elkington 1968) or pre/post-expedition in the experimenter's home country at a constant elevation (15-1750 m above sea level) (Wyndham et al. 1964; Naidu and Sachdeva 1993; Rintämäki et al. 1993). Keramidas et al.'s (2018) study is the exception, and data from this short (11 days) polar trek support the notion that peripheral adaptations to the cold may occur although the exposure duration may have been sub-optimal (Daanen and van Ruiten 2000). The aim of the present study was to investigate the effect of a prolonged (almost 8-month) trans-Antarctica winter traverse on the CIVD responses to cold exposure and to quantify the timecourse of any adaptations. The project was conducted as part of The Coldest Journey White Mars Science Group.

\section{Materials and methods}

\section{Participants}

Six male Caucasian participants provided oral and written informed consent prior to participating. All participants were members of the Trans-Antarctica Winter Traverse expedition team and the Coldest Journey White Mars Science Group, who were attempting to cross Antarctica. During the initial depot-laying journey, the expedition leader developed second-degree frostbite and returned home, taking no further part in the expedition. The five remaining participants had a pre-expedition median (range) age of 35 (29-54) years, stature of $172(170-178) \mathrm{cm}$ and body mass of $83(65-86) \mathrm{kg}$. Two participants had no prior polar experience; one participant had experience of Antarctic summer seasons; one participant had experience of winter and summer seasons in Antarctica; and one participant had experienced multiple summer and winter seasons in Antarctica and the Arctic Circle. All participants were right-handed, all were non-smokers at the time of the expedition (two had recently stopped smoking), and none suffered from Raynaud's syndrome. The study was approved by the University of Roehampton's Ethical Advisory Committee.

\section{The expedition}

Following the expedition leader's exit, the five remaining team members started the expedition using vehicles on the $21 \mathrm{st}$ of March 2013. After travelling approximately $335 \mathrm{~km}$ and reaching Camp 24 ( $\left.72^{\circ} 54^{\prime} 20.4^{\prime \prime} \mathrm{S}, 023^{\circ} 35^{\prime} 08.0^{\prime \prime} \mathrm{E}\right)$ on the 9th of May 2013, the expedition was abandoned due to the danger posed by the crevasses encountered. A semi-permanent camp was established for the next 5 months during which time the group was largely sedentary, although daily checks of the campsite and equipment, together with outside exercise when conditions allowed, provided some degree of activity. On the 24th of September 2013 the team began returning towards their start point at Crown Bay. The final 
camp was made near Princess Elizabeth Station ( $\left.71^{\circ} 57^{\prime} \mathrm{S}\right)$, from where the team were flown home (November 2013).

\section{Experimental procedures}

Data were collected on the days that data were able to be collected: 12th, 39-40th, 67-68th, 179th and 234th days of the expedition (see Table 1 for temperature and altitude data on each day). The recorded elevation was likely to be lower than the effective altitude, especially during the colder months where the partial pressure of oxygen $\left(\mathrm{P}_{\mathrm{I}} \mathrm{O}_{2}\right)$ was more likely to correspond to approximately $3300 \mathrm{~m}$ (West et al. 1983; West 2001). The conditions in the caboose were not recorded but were maintained so that participants could comfortably wear light trousers and a t-shirt (Lambert, personal communication). Participants wore their usual attire and sat quietly throughout each testing session. Each testing session lasted $40 \mathrm{~min}$ and involved $5 \mathrm{~min}$ of instrumentation, $30 \mathrm{~min}$ of immersion of the index finger of their non-dominant hand up to the proximal knuckle into an icebox $[221(\mathrm{H}) \times 158$ $(\mathrm{W}) \times 75(\mathrm{D}) \mathrm{mm}$ ] filled with $2 \mathrm{~L}$ of ice and water. Water temperature was recorded at 1-min intervals. CIVD tests took place at the same time of day $(16: 00 \pm 1 \mathrm{~h})$ on each occasion.

\section{Measurements}

Skin thermistors (THERM 37904, Viamed Ltd, U.K.) were used to measure the temperature of the skin lateral to the nail bed of the immersed index finger and the temperature of the skin superior to the sternal notch. Both thermistors were attached using a single layer of transparent dressing (Transpore White, 3M Health Care, USA), connected to a digital reader (Thermistor Thermometer 5831, DigiTec Corporation, USA). Skin temperatures were recorded at 1-min intervals during the immersion (0-30 min).

Table 1 Environmental data during CIVD testing

\begin{tabular}{|c|c|c|c|c|c|}
\hline Day of expedition (\#) & 12 & $39-40$ & $67-68$ & 179 & 234 \\
\hline Date & $02 / 04$ & $29-30 / 04$ & $27-28 / 05$ & $16 / 09$ & $11 / 11$ \\
\hline Temperature $\left({ }^{\circ} \mathrm{C}\right)$ & -16 & -34 & -33 & -44 & -11 \\
\hline $\begin{array}{l}\text { Elevation above sea } \\
\text { level }(\mathrm{m})^{*}\end{array}$ & 1296 & 2696 & 2752 & 2752 & 1367 \\
\hline $\begin{array}{l}\text { Barometric pressure } \\
(\mathrm{mmHg})\end{array}$ & 617 & 514 & 511 & 512 & 624 \\
\hline $\begin{array}{l}\text { Estimated } \mathrm{Pi}_{\mathrm{O} 2} \\
\quad(\mathrm{mmHg})^{*}\end{array}$ & 119 & 98 & 97 & 97 & 121 \\
\hline
\end{tabular}

$\mathrm{Pi}_{\mathrm{O} 2}$ estimated using the following equation: $\mathrm{Pi}_{\mathrm{O} 2}=\mathrm{F}_{\mathrm{I}} \mathrm{O}_{2} \times$ (Barometric pressure - saturated vapour pressure of water)

*Effective altitude is likely to have been higher and so actual $\mathrm{Pi}_{\mathrm{O} 2}$ may have been lower than estimation (West et al. 1983; West 2001)
Heart rate (HR; Polar Electro Oy, Kempele, Finland) was recorded at baseline and at 5-min intervals throughout the immersion (0-30 $\mathrm{min})$ and recovery phases (30-35 min). Blood pressure was measured on the dominant, supported arm whilst participants were seated using a digital sphygmometer (UA767 Digital blood pressure monitor, A\&D Company Ltd., Tokyo, Japan) before and after the 30-min immersion. Due to time constraints, repeat measurements were only taken if the initial test resulted in an error message. Mean arterial pressure (MAP) was calculated using the formula $\left.\left(\mathrm{DBP}^{*} 2\right)+\mathrm{SBP}\right] / 3$ (where $\mathrm{DBP}=$ diastolic blood pressure and $\mathrm{SBP}=$ systolic blood pressure).

Every 5 min participants were asked to rate their thermal sensation (TS) for the immersed finger using a nine-point scale ranging from 0 (unbearably cold) to 8 (unbearably hot) with 4 as comfortable (neutral) (Young et al. 1987) and their level of pain sensation (PS) using a Numeric Pain Distress scale ranging from 0 (no pain) to 10 (unbearable pain) (Daanen et al. 2012).

Outside temperature and pressure, and the elevation above sea level of the caboose was measured at $0600 \mathrm{~h}$ and $1800 \mathrm{~h}$ each day. Mean data were calculated from these data for each day and are presented in Table 1. The partial pressure of oxygen was estimated using these meteorological data. Approximate outside exposure time was derived from contemporaneous diary records.

\section{Data analyses}

Data are presented as median (range) unless stated. Individual overall mean, minimum, maximum, and recovery temperatures were calculated from each CIVD test and the median of these data is presented. The median and total number of CIVD responses as well as the amplitude, onset time and peak time of the 1st CIVD response were calculated using the following definitions (Daanen 2003; Mekjavic et al. 2013):

1. Number of waves $(\mathrm{N})$ : to be characterised as a CIVD response an increase in temperature of $>0.5{ }^{\circ} \mathrm{C}$ lasting for $\geq 3 \mathrm{~min}$ must have been observed.

2. Minimum temperature $\left(\mathrm{T}_{\min }\right)$ : the lowest temperature prior to the onset of CIVD

3. Maximum temperature $\left(\mathrm{T}_{\max }\right)$ : the highest temperature during the CIVD

4. Mean temperature $\left(\mathrm{T}_{\text {mean }}\right)$ : the mean temperature during the water immersion period (5-30 min)

5. Temperature amplitude $(\Delta \mathrm{T}): \mathrm{T}_{\max }-\mathrm{T}_{\min }$

6. Peak time $\left(\Delta \mathrm{t}_{\text {peak }}\right)$ : time interval between $\mathrm{T}_{\text {min }}$ and $\mathrm{T}_{\text {max }}$

7. Onset time $\left(\Delta \mathrm{t}_{\text {onset }}\right)$ : time between immersion and $\mathrm{T}_{\min }$ 
In addition, the area under the curve (AUC) was calculated for finger skin temperature data using the trapezoidal method.

Comparisons were made to study the separate and interactive effects of cold and altitude acclimatisation:

1. Data from days 12 to 234 to investigate the overall effect of the expedition, and

2. Data from day 12 to 179 (inclusive) to investigate the effect of short-term and prolonged hypobaric hypoxia.

Wilcoxon signed-rank tests were conducted and effect sizes $(r)$ were calculated from the resultant $z$ score. Effect sizes were interpreted using the following classifications: $r<0.1=$ trivial $;=0.1-0.3=$ small $; r=0.3-0.5=$ moderate effect; $r>0.5=$ large effect. Due to the small sample size, only moderate or large effect sizes are discussed. Kendall's tau $(\tau)$ correlation analyses were run to investigate the relationship between median perceptual and temperature data.

\section{Results}

Between April and October, participants spent a median of 111 (8-360) min each day outside of the caboose undertaking low-intensity work. The median total duration working outside of the caboose was 949 min although individual differences were present (individual durations: 650, 778, 949, 1004 and $1603 \mathrm{~min}$ ). Ambient testing conditions resulted in chest skin temperatures of 33.4 (31.5-34.1) ${ }^{\circ} \mathrm{C}$. Immersion water temperature was maintained at $0.0(-0.1-0.4){ }^{\circ} \mathrm{C}$.

\section{Finger temperatures}

$\mathrm{T}_{\text {mean }}, \mathrm{T}_{\min }$ and $\mathrm{T}_{\max }$ data are presented in Fig. 1. The expedition overall had a small effect on increasing $\mathrm{T}_{\text {min }}$ from day 12 to day $234(r=0.21)$ but a large effect on increasing $\mathrm{T}_{\max }$ $(r=0.64)$ and $\mathrm{T}_{\text {mean }}(r=0.64)$ over the same period. $\mathrm{T}_{\max }$ and $\mathrm{T}_{\text {mean }}$ were greater on day 234 than day 12 in all 5 participants and $\mathrm{T}_{\min }$ was greater in 4 of the 5 participants. Previous polar experience did not appear to have an influence on cold adaptation rate or magnitude. Although the greatest increase in $\mathrm{T}_{\text {mean }}$ between day 12 and 234 was observed in one of the two polar novices (filled square marker in Figs. 1a), the other novice (cross marker in Fig. 1a) demonstrated the smallest increase. The greatest adaptation in $\mathrm{T}_{\min }$ and $\mathrm{T}_{\max }$ was observed in the most (diamond marker in Fig. 1b and c) and third (open circle marker in Fig. 1b and c) most experienced members of the expedition team, respectively.

There was a small increase during the move up to high altitude from day 12 to day 39 for $\mathrm{T}_{\min }(r=0.23 ; 2 / 5$ participants showed an increase $)$ and $\mathrm{T}_{\max }(r=0.13 ; n=2 / 5$ participants showed an increase), but no effect on $\mathrm{T}_{\text {mean }}$
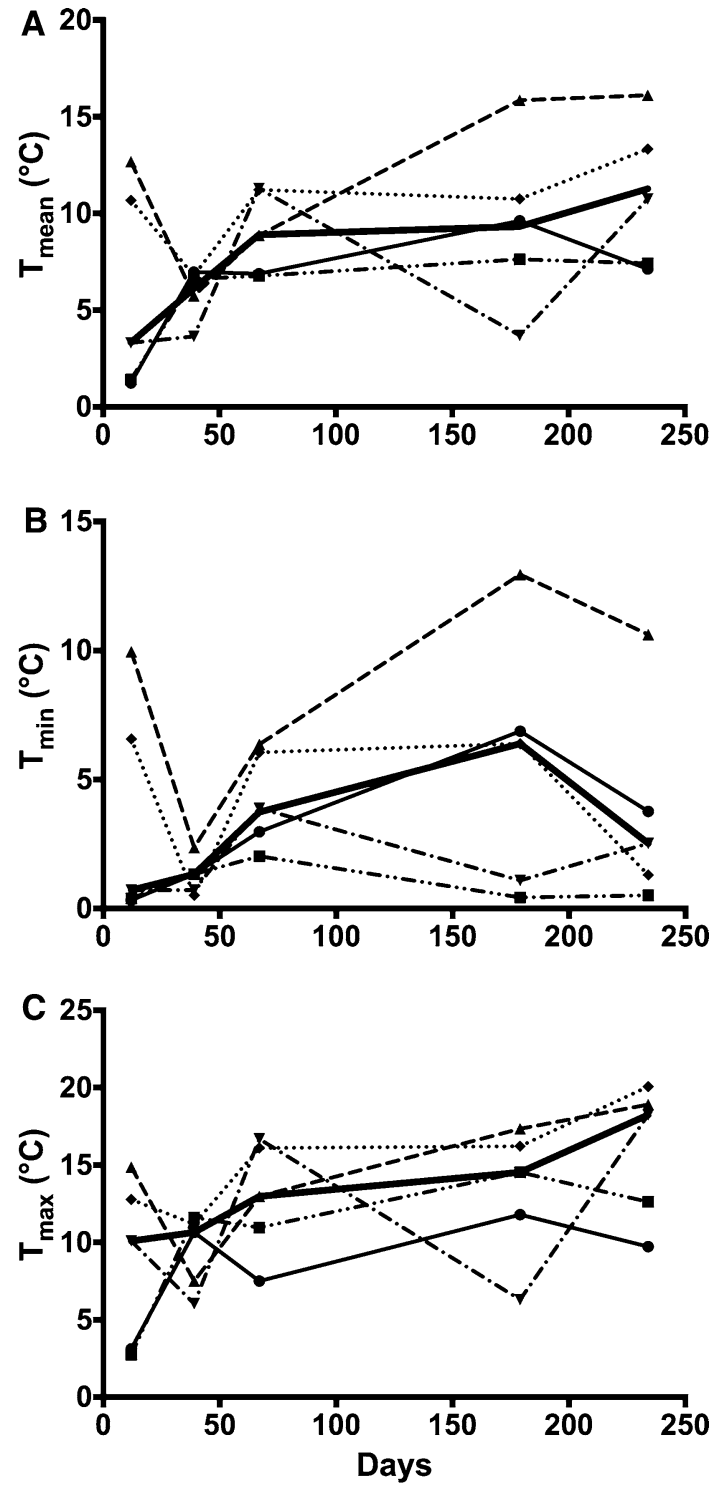

Fig. 1 Mean (a), minimum (b), and maximum (c) finger temperatures during finger immersion over the course of the expedition. Grey lines denote individual responses. Black lines denote median response

( $r=0.04 ; n=3 / 5$ participants showed an increase). Comparing day 12 to day 67, the 55 extra days in Antarctica and movement to altitude had a small effect on increasing $\mathrm{T}_{\min }(r=0.13 ; n=3 / 5$ participants showed an increase), a large effect on increasing $\mathrm{T}_{\max }(r=0.55 ; n=4 / 5$ participants showed an increase), and a moderate effect on increasing $\mathrm{T}_{\text {mean }}(r=0.47 ; n=4 / 5$ participants showed an increase). When at a fixed altitude of $2752 \mathrm{~m}$, the period of time from day 67 to day 179 had a small effect on increasing $\mathrm{T}_{\min }, \mathrm{T}_{\max }$ and $\mathrm{T}_{\text {mean }}(r=0.21$ for all; $n=3 / 5, n=4 / 5$, and $n=4 / 5$ participants showed an increase respectively). The descent from 2752 (day 179) to $1367 \mathrm{~m}$ (day 234) had a moderate effect on decreasing $\mathrm{T}_{\min }(r=0.38 ; n=3 / 5$ participants showed a 
decrease) whilst increasing $\mathrm{T}_{\text {mean }}(r=0.30 ; n=2 / 5$ participants showed a decrease), and a small effect on increasing $\mathrm{T}_{\max }(r=0.21 ; n=2 / 5$ participants showed a decrease). The finger temperature AUC was greater at every subsequent time-point (Table 2).

\section{CIVD responses}

Table 2 summarises most of the CIVD data. All five participants had at least one CIVD episode on each testing occasion. The expedition (day 12 vs. day 234) had a moderate effect on inducing an earlier onset time $(r=0.34 ; n=4 / 5$ participants showed an earlier response) and a large effect on increasing the amplitude of the response $(r=0.55 ; n=4 / 5$ participants showed a greater response). Short-term hypobaric cold exposure (12 vs. 39 days) had a moderate effect on inducing an earlier CIVD response ( $r=0.47 ; n=4 / 5$ participants showed an earlier response) and a greater amplitude ( $r=0.47 ; n=4 / 5$ participants showed a greater response) and these variables were further enhanced after an additional 28 days ( 12 days vs. 67 days: Onset time: $r=0.58 ; n=4 / 5$ participants showed an earlier response; amplitude: $r=0.64$; $n=5 / 5$ participants showed an earlier response). The peak time was greater after 67 days than 12 days $(r=0.30 ; 4 / 5$ participants showed a longer response). Onset time was later at day 179 compared to day $67(r=0.64 ; n=5 / 5$ participants showed a later response) but neither peak time ( $r=0.09 ; n=2 / 5$ participants showed a greater response) nor the amplitude $(r=0.21 ; n=1 / 5$ participants showed a greater response) was negatively affected by the prolonged stay at a stable altitude. Returning to a lower altitude after the prolonged stay at $2752 \mathrm{~m}$ (day 179 vs. day 234) had a moderate effect on reducing the onset time $(r=0.47$; $n=4 / 5$ participants showed an earlier response) and increasing the amplitude $(r=0.38 ; n=3 / 5$ participants showed a greater response) but a small effect on increasing peak time ( $r=0.12 ; n=2 / 5$ participants showed a greater response).

\section{Cardiovascular responses}

Cardiovascular data are presented in Table 3. The expedition had a moderate effect on decreasing pre- and post-MAP ( $r=0.47$ and $r=0.47$ ), a small effect on decreasing pre-SBP $(r=0.13)$ and post-DBP $(r=0.29)$, and a large effect on reducing pre-DBP $(r=0.64)$ and post-SBP $(r=0.64)$ from day 12 to day 234. Mean HR was higher during the CIVD test on day 234 than day $12(r=0.55)$.

There was a small decrease from day 12 to day 39 for pre- and post-MAP $(r=0.23$ and $\mathrm{r}=0.13)$, pre- and post$\operatorname{SBP}(r=0.21$ and $r=0.17)$ and pre- and post-DBP $(r=0.26$ and $r=0.13$ ). HR was higher during the test on day 39 than day $12(r=0.51)$. An extra 55 days in Antarctica had a small effect on decreasing pre-test DBP $(r=0.23)$, a moderate effect on decreasing pre-MAP $(r=0.38)$ and pre-SBP $(r=0.47)$, a moderate effect on increasing HR $(r=0.30)$, and a large effect on decreasing post-test MAP $(r=0.64)$, $\mathrm{SBP}(r=0.64)$ and DBP $(r=0.55)$. The extended stay at a fixed altitude of $2752 \mathrm{~m}$ (day 67 to day 179) had no effect on pre-MAP $(r=0.04)$ but a large effect on increasing posttest MAP $(r=0.51)$. The extended stay had a small effect on increasing pre-DBP $(r=0.17)$, a moderate effect on increasing pre-test SBP $(r=0.39)$ and post-test DBP $(r=0.39)$,

Table 2 Median (range) cold-induced vasodilation data during the trans-Antarctic Winter traverse

\begin{tabular}{|c|c|c|c|c|c|c|}
\hline & & Day 12 & Day 39-40 & Day 67-68 & Day 179 & Day 234 \\
\hline Area under the curve & ${ }^{\circ} \mathrm{C} \min ^{-1}$ & $96(38-350)$ & $195(138-201)^{\mathrm{b} 12}$ & $263(199-333)^{\mathrm{b} 12 \mathrm{~b} 39}$ & $\begin{array}{l}289(168- \\
400)^{\text {b12 b39 a } 67}\end{array}$ & $\begin{array}{l}321(217-443)^{\mathrm{b} 12 \mathrm{~b} 39} \\
\text { b67 a179 }\end{array}$ \\
\hline \multicolumn{7}{|l|}{ CIVD1 } \\
\hline Responders & $\mathrm{N}(\%)$ & $5(100 \%)$ & $5(100 \%)$ & $5(100 \%)$ & $5(100 \%)$ & $5(100 \%)$ \\
\hline Onset time $\left(\Delta t_{\text {onset }}\right)$ & Min & $11(9-15)^{\mathrm{a} 39, \mathrm{a} 234, \mathrm{~b} 67}$ & $11(6-11)$ & $7(4-9)^{\mathrm{b} 179}$ & $12(8-16)^{\mathrm{a} 234}$ & $7(6-18)$ \\
\hline Peak time $\left(\Delta t_{\text {peak }}\right)$ & Min & $13(3-17)^{\mathrm{a} 67}$ & $10(6-11)$ & $11(4-13)$ & $8(3-14)^{b 234}$ & $8(4-22)$ \\
\hline Amplitude $(\Delta T)$ & ${ }^{\circ} \mathrm{C}$ & 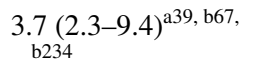 & $9.3(5.1-10.7)$ & $8.9(4.5-10.3)$ & $5.2(2.1-14.1)^{\mathrm{a} 234}$ & $12.1(4.0-18.8)$ \\
\hline \multicolumn{7}{|l|}{ CIVD2 } \\
\hline Responders & $\mathrm{N}(\%)$ & $2(40 \%)$ & $1(20 \%)$ & $4(80 \%)$ & $1(20 \%)$ & $1(20 \%)$ \\
\hline Onset time $\left(\Delta t_{\text {onset }}\right)$ & Min & $21(19-23)$ & 25 & $19.5(14-23)$ & 18 & 22 \\
\hline Peak time $\left(\Delta t_{\text {peak }}\right)$ & Min & $3(3-4)$ & 5 & $6(2-11)$ & 3 & 6 \\
\hline Amplitude $(\Delta T)$ & ${ }^{\circ} \mathrm{C}$ & $3.0(2.2-3.7)$ & 1.1 & $4.0(3.1-5.0)$ & 3.1 & 7.5 \\
\hline
\end{tabular}

CIVD1 1st cold-induced vasodilation wave, CIVD2 2nd cold-induced vasodilation wave

${ }^{a}$ Moderate effect size $(r=0.3<0.5)$ compared to the day numbered

${ }^{\mathrm{b}}$ Large effect size $(r \geq 0.5)$ compared to the day numbered. Due to the number of responses effect size data were only calculated for the 1 st CIVD response 
Table 3 Median (range) cardiovascular and perceptual data during the expedition

\begin{tabular}{|c|c|c|c|c|c|c|}
\hline & & Day 12 & Day 39-40 & Day 67-68 & Day 179 & Day 234 \\
\hline \multicolumn{7}{|c|}{ Cardiovascular variables [blood pressure $(\mathrm{mmHg})$; heart rate $(\mathrm{b} \mathrm{min}-1)]$} \\
\hline \multirow[t]{2}{*}{ SBP } & Pre & $109(101-120)^{\mathrm{a} 67}$ & $103(100-130)^{\mathrm{b} 67}$ & $99(90-114)^{\mathrm{a} 179}$ & $103(94-112)$ & $102(94-124)$ \\
\hline & Post & $110(96-118)^{\mathrm{b} 67, \mathrm{~b} 234}$ & $109(104-127)^{b 67}$ & $98(92-103)^{b 179}$ & $101(94-133)$ & $106(92-109)$ \\
\hline \multirow[t]{2}{*}{ DBP } & Pre & $82(64-86)^{\mathrm{b} 234}$ & $72(68-79)$ & $69(61-86)$ & $71(64-79)^{\mathrm{a} 234}$ & $67(63-76)$ \\
\hline & Post & $72(61-85)^{\mathrm{b} 67}$ & $74(71-77)^{\mathrm{a} 67}$ & $69(58-77)^{\mathrm{a} 179}$ & $71(67-87)$ & $70(64-78)$ \\
\hline \multirow[t]{2}{*}{ MAP } & Pre & $88(79-88)^{\mathrm{a} 67, \mathrm{a} 234}$ & $83(80-91)^{\mathrm{a} 67}$ & $78(71-95)$ & $84(74-90)$ & $77(73-92)$ \\
\hline & Post & $87(73-93)^{\mathrm{a} 234, \mathrm{~b} 67}$ & $87(82-92)^{\mathrm{b} 67}$ & $78(69-86)^{\mathrm{b} 179}$ & $82(78-102)$ & $82(77-87)$ \\
\hline \multicolumn{2}{|c|}{$\mathrm{HR}_{\text {mean }}$} & $71(68-81)^{\mathrm{b} 39, \mathrm{a} 67, \mathrm{~b} 234}$ & $78(73-84)^{\mathrm{a} 67}$ & $76(71-85)^{\mathrm{b} 179}$ & $81(75-89)$ & $80(75-86)$ \\
\hline \multicolumn{7}{|c|}{ Perceptual variables [thermal sensation $(0-8)$; pain sensation $(0-10)]$} \\
\hline \multicolumn{2}{|c|}{$\mathrm{TS}_{\text {mean }}$} & $2(1-3)^{\mathrm{b} 39, \mathrm{~b} 67, \mathrm{~b} 234}$ & $3(2-4)^{\mathrm{a} 67}$ & $3(2-3)$ & $3(1-4)$ & $3(3-4)$ \\
\hline \multicolumn{2}{|l|}{$\mathrm{TS}_{\text {peak }}$} & $4(4-5)^{\mathrm{a} 234}$ & $4(4-5)$ & $5(3-5)$ & $4(4-5)^{\mathrm{a} 234}$ & $5(4-6)$ \\
\hline \multicolumn{2}{|l|}{$\mathrm{PS}_{\text {mean }}$} & $2(0-4)^{\mathrm{a} 39, \mathrm{~b} 67, \mathrm{~b} 234}$ & $1(0-1)$ & $0(0-1)$ & $0(0-1)^{\mathrm{a} 234}$ & $0(0-1)$ \\
\hline \multicolumn{2}{|l|}{$\mathrm{PS}_{\text {peak }}$} & $4(2-8)^{\mathrm{b} 67, \mathrm{a} 234}$ & $4(1-5)^{\mathrm{b} 67}$ & $2(0-3)$ & $1(0-3)^{\mathrm{a} 234}$ & $3(0-4)$ \\
\hline
\end{tabular}

${ }^{a}$ Moderate effect size $(r=0.3<0.5)$ compared to the day(s) numbered

${ }^{\mathrm{b}}$ Large effect size $(r \geq 0.5)$ compared to the day numbered and a large effect on increasing post-test $\operatorname{SBP}(r=0.55)$ and mean HR $(r=0.55)$. The descent from 2752 (day 179) to $1367 \mathrm{~m}$ (day 234) had no effect on post-test MAP $(r<0.01)$ or mean HR $(r=0.04)$ but a small effect on decreasing pretest MAP $(r=0.21)$, decreasing pre-test SBP $(r=0.17)$, increasing post-test SBP $(r=0.21)$ and decreasing post-test DBP $(r=0.13)$. The return to a lower altitude also had a moderate effect on reducing pre-test DBP $(r=0.47)$.

\section{Perceptual responses}

The mean and peak level of perceived thermal sensation and pain are shown in Table 3. Thermal sensation and perceived pain both improved over the course of the expedition, mean and peak thermal sensation were lowest on day 12 and highest on day $234(r=0.59 ; r=0.31)$, whilst mean and peak perceived pain decreased from day 12 to day $234(r=0.58$; $r=0.36$ ).

There was a strong, positive correlation between TS and finger temperature $(\tau=0.56 ; p<0.0001)$ and strong, negative correlations between PS and finger temperature $(\tau=-0.68$; $p<0.0001)$ and between PS and TS $(\tau=-0.66 ; p<0.0001)$.

\section{Discussion}

An earlier and greater CIVD response would be advantageous because the increased blood flow would minimise extremity cooling, potentially decreasing cold injury risks. Participants had overall positive CIVD adaptations to cold and altitude during 9 months in Antarctica; perceived thermal sensation and pain also improved over the expedition. MAP was lowered during the expedition due to moderateto-large reductions in post-testing SBP and pre-testing DBP.
These adaptations occurred progressively over the expedition, but the rate of onset differed between variables.

\section{CIVD and finger temperature responses}

By comparing the 1st (day 12) and last (day 234) measurements, these data show that participants made some positive adaptions to the cold during the course of the expedition with an earlier onset time for the 1st wave CIVD, greater maximum and mean finger temperatures, and a larger 1st wave CIVD amplitude. These adaptations occurred over the duration of the expedition but time-point data suggest that the rate of onset differed between variables as the participants were exposed to low temperatures and hypoxic conditions.

Acute exposure to altitude can reduce the CIVD response in lowland natives, such as those in the present study, (Mathew et al. 1977; Daanen and van Ruiten 2000) but stronger CIVD responses have been observed following prolonged hypoxic exposure (21 days (Felicijan et al. 2008), 28 days (Amon et al. 2012), and 45 days (Daanen and van Ruiten 2000) days). For logistical reasons the 1st CIVD test was not conducted until the 12th day of the expedition in the present study and so the acute phase was missed and direct comparisons with the recent study reporting the responses to an 11-day Antarctic expedition are not possible (Keramidas et al. 2018). Keramidas et al. (2018) observed that although cutaneous vasoconstriction was somewhat blunted, CIVD responses were unaffected. Similarly, during the earliest phase of the expedition following the first test (days 12-39 when the majority of the elevation was gained) minimum, maximum, and mean finger temperatures were largely unaffected by medium-term hypobaric, cold exposure but the first wave CIVD onset and amplitude was earlier and greater, 
respectively. After 67 days, minimum finger temperatures remained similar to day 12 but maximum and mean temperatures were now higher. The first wave CIVD onset time was earlier still and the amplitude was further increased whilst the peak time was greater. These data suggest an increase in peripheral blood flow and an enhanced maintenance of tissue temperature during the immersion test and indicate beneficial peripheral adaptions to the cold, hypoxic conditions during the earliest phase. During the main body of the expedition (days 39-179) participants were at an altitude of 2696-2752 m [estimated $\mathrm{P}_{\mathrm{I}} \mathrm{O}_{2}=97-98 \mathrm{mmHg}$ ), which allowed for the effect of cold exposure to be considered without the confounding effect of hypoxia. Finger temperatures (min, max, and mean), CIVD peak time, and CIVD amplitude were unaffected during this period but the first CIVD response was delayed on day 179 compared to day 67. These data suggest that the meaningful adaptations to the sustained combination of cold and hypoxia occurred in the initial 67 days of the expedition and that the additional exposure had no further additive effect and is similar to the data of Purkayastha et al. (1992) who reported positive adaptations following 7 weeks of polar exposure. The only difference between data from the 67th to 179th day of the expedition was a delayed first CIVD wave response. This could be viewed as a negative event because it would prolong the time spent at low temperatures before warming occurred; however, it may be an indirect marker of positive adaptation because the increase in finger temperatures observed might delay the time taken to reach a triggering onset temperature and the progressive increase in finger temperature AUC supports this.

Natural acclimatisation to cold has been reported to shorten (Nelms and Soper 1962) or have no effect (Felicijan et al. 2008) on CIVD onset time in pre-adapted populations (fishermen and alpinists respectively) and so the current data differ from that previously reported. The difference in data may be due to the lower levels of pre-adaption in the present group or the well-documented variability of CIVD measures (e.g. Felicijan et al. 2008) but the exact reason(s) remains to be elucidated. The onset time was earlier following the descent from 2752 (day 179; estimated $\mathrm{P}_{\mathrm{I}} \mathrm{O}_{2}=97 \mathrm{mmHg}$ ) to $1367 \mathrm{~m}$ (day 234; estimated $\mathrm{P}_{\mathrm{I}} \mathrm{O}_{2}=121 \mathrm{mmHg}$ ); however, the descent was matched with an increase in ambient temperature and so it is not possible to know whether this change was altitude or cold dependent (or co-dependent). In combination, these data suggest that peripheral adaptation to the cold can occur but that different variables adapt at different rates with the CIVD wave onset and amplitude showing positive adaptions in advance of skin temperature data. An earlier and greater CIVD response would be advantageous because it would minimise the time that the periphery spent very cold whilst maximising the warm blood redistributed back to the at-risk region.

\section{Cardiovascular responses}

The understanding of longitudinal cardiovascular responses to cold and altitude adaptation remains minimal. Much of the research on cold effects on cardiovascular parameters involve retrospective, epidemiological studies on ambient temperatures and cardiovascular-related deaths (Liu et al. 2011). Some longitudinal field studies on mountaineers have been conducted, such as the American Medical Research Expedition to Everest focusing on resting ECG parameters (Karliner et al. 1985). MAP was lowered during the expedition due to reductions in post-testing SBP and pre-testing DBP. The decrease was progressive with moderate-to-large reductions observed in pre- and post-MAP from day 12 to day 67 as a result of moderate-to-large reductions in preand post-SBP, and post-DBP. Whilst overall blood pressures were reduced, increases in pre- and post-SBP, post-DBP, and post-test MAP were observed during the period of sustained altitude exposure between day 67 and 179. Acute cold exposure increased MAP and such elevations have been attributed to a higher sympathetic activation (Sendowski et al. 1997; Mekjavic et al. 2013; Tyler et al. 2015). In the present study the magnitude of cold exposure during the CIVD test was consistent throughout the expedition $\left(0{ }^{\circ} \mathrm{C}\right.$ water temperature) and a reduction in MAP was observed in all comparisons except for pre-test MAP at day 67 vs. 179 (where the elevation was constant) and post-test MAP at day 179 vs. 234 during which time a descent of $1385 \mathrm{~m}$ was made. The reduction in MAP suggests that the participants may have adapted to the cold and experienced lower sympathetic activation during the CIVD tests; however, the elevated HR data refutes this. Mean HR showed a progressive increase throughout the expedition with higher mean HRs $(r=0.30-0.55)$ recorded at each time-point compared to baseline. The highest mean HR was recorded on day 179 and the descent from 2752 to $1367 \mathrm{~m}$ had no effect on this mean HR. These data suggest that the participants did not have lower sympathetic activation during the CIVD tests and that altitude did not impact upon these data because even when at a fixed altitude, mean HR increased over time. Future studies performing longitudinal tracking of cardiovascular coupled with autonomic changes to cold exposure and/or altitude appear warranted to deepen our understanding of cardiovascular adaptations to extreme environments.

\section{Perceptual responses}

Although the changes were small, the perceived thermal sensation and pain levels improved throughout the expedition so that participants reported feeling less cold and less pain at the end of the expedition compared to the beginning. There was a strong, positive correlation between TS and finger temperature, and strong, negative correlations between 
PS and finger temperature and between PS and TS, and so these data are likely to be due to the peripheral adaptions discussed above. Acute cooling of the skin to temperatures below $20{ }^{\circ} \mathrm{C}$ activates polymodal nociceptor neurons and causes unpleasant thermal sensations and pain (Belmonte et al. 2009) and whilst these data suggest that prolonged cold exposure may alter this response, as with the data above, these data should be interpreted with caution due to the low sample size. Reductions in pain sensation following repeated cold exposure without accompanying increases in finger skin temperature may increase the risk of cold injuries because individuals are less likely to take preventative measures (e.g. apply gloves) (Daanen et al. 2012); however, in the present study, reductions in pain sensation were matched with increases in finger skin temperature suggesting a safe improvement in pain and thermal perception during the expedition.

\section{Conclusion}

In conclusion, despite spending the majority of the time in a climate-controlled caboose on the ice-shelf, beneficial peripheral and perceptual adaptations to prolonged Antarctic exposure can occur with approximately $2 \mathrm{~h}$ of daily outdoor exposure. The rate at which physiological adaptions occur appear to differ with CIVD wave onset and amplitude, and perceptual adaptions occurring in advance of changes in skin temperature. Future expedition research should look to establish the mechanisms behind long-term cold adaptation.

\section{Limitations and considerations}

Due to the logistically challenging experimental set-up, a number of limitations exist. One such limitation of the current manuscript is the low sample size $(N=5)$; however, this sample size is similar to other expedition projects (Keramidas et al. 2018). Whilst expedition data have been collected and reported previously, this is the longest CIVD field data collection known to the authors and, albeit fortuitously, the longest polar expedition with a period of fixed altitude allowing cold adaption to be investigated without the confounding effect of hypoxia.

Expeditions such as this provide researchers with a rarely accessible research environment; however, they also provide researchers with methodological challenges. The CIVD response may have a central origin and be dependent upon core body temperatures (Flouris et al. 2008); however, in the present study neither the caboose nor body temperatures were recorded due to the logistical challenges of doing so. The lack of such data is a limitation but it is worth noting that the median chest temperature was consistent between trial days [33.4 (31.5-34.1) $\left.{ }^{\circ} \mathrm{C}\right]$ and that the caboose was maintained at a temperature allowing participants to "wear light trousers and a t-shirt" (personal correspondence: Dr Rob Lambert) so it is likely that body temperatures were comparable on testing days. In addition, due to logistical constraints, a true baseline was not measured and all data are compared to day 12. Data collected on day 12 may be lower than they would have been on day 0 due to transient reductions in finger skin temperature caused by the initial exposure to the stressors; however, 11 days seems insufficient to induce meaningful adaptations (Keramidas et al. 2018). Finally, greater hand width and shorter digit length have been proposed as evolutionary adaptations against heat loss and cold injuries (Payne et al. 2018). Whilst this was not recorded in our participants, the trends in adaptive responses remain valid due to each participant serving as their own control.

Due to logistics (i.e. the high availability of ice), the present investigation used $0{ }^{\circ} \mathrm{C}$ water for the immersion although $8^{\circ} \mathrm{C}$ is the water temperature most commonly used in CIVD research (Cheung and Daanen 2012). Water at a temperature of $8{ }^{\circ} \mathrm{C}$, rather than $0{ }^{\circ} \mathrm{C}$, should be used when looking to optimise the number of CIVD waves observed and minimise participant discomfort (Mekjavic et al. 2013; Tyler et al. 2015); however, $0{ }^{\circ} \mathrm{C}$ is a commonly used water temperature out of the laboratory environment due to its easy achievement with a combination of water and snow/ice (Daanen and van Ruiten 2000; Daanen and van der Struijs 2005). Immersion in water at $0{ }^{\circ} \mathrm{C}$ results in a delayed $1 \mathrm{st}$ CIVD response, a more pronounced and longer wave, lower finger temperatures and colder sensations than immersion in $8{ }^{\circ} \mathrm{C}$ (Tyler et al. 2015) and this should be considered when comparing the data from this investigation with data using $8{ }^{\circ} \mathrm{C}$ water.

Acknowledgements The authors would like to thank the participants for their time and Dr Geoffrey Hartley for his assistance with the equipment. None of the authors have any commercial interests or other conflicts of interest to declare nor did they receive any funding to assist with the preparation of this manuscript. S.S. Cheung is supported by a Canada Research Chair. The experiment outlined in this manuscript complies with the current laws of the United Kingdom and received full ethical approval. This study was conducted as part of The White Mars Project and The Coldest Journey expedition (www.thecoldest journey.org).

Open Access This article is licensed under a Creative Commons Attribution 4.0 International License, which permits use, sharing, adaptation, distribution and reproduction in any medium or format, as long as you give appropriate credit to the original author(s) and the source, provide a link to the Creative Commons licence, and indicate if changes were made. The images or other third party material in this article are included in the article's Creative Commons licence, unless indicated otherwise in a credit line to the material. If material is not included in the article's Creative Commons licence and your intended use is not permitted by statutory regulation or exceeds the permitted use, you will need to obtain permission directly from the copyright holder. To view a copy of this licence, visit http://creativecommons.org/licenses/by/4.0/. 


\section{References}

Adams T, Smith RE (1962) Effect of chronic local cold exposure on finger temperature responses. J Appl Physiol 17:317-322

Amon M, Keramidas ME, Kounalakis SN, Mekjavic IB (2012) The effect of a sleep high-train low regimen on the finger cold-induced vasodilation response. High Alt Med Biol 13:32-39

Belmonte C, Brock JA, Viana F (2009) Converting cold into pain. Exp Brain Res 196:13-30

Cheung SS, Daanen HA (2012) Dynamic adaptation of the peripheral circulation to cold exposure. Microcirculation 19:65-77

Daanen HA (2003) Finger cold-induced vasodilation: a review. Eur J Appl Physiol 89:411-426

Daanen HA, Koedam J, Cheung SS (2012) Trainability of cold induced vasodilatation in fingers and toes. Eur J Appl Physiol 112:2595-2601

Daanen HA, van der Struijs NR (2005) Resistance Index of Frostbite as a predictor of cold injury in arctic operations. Aviat Space Environ Med 76:1119-1122

Daanen HA, van Ruiten HJ (2000) Cold-induced peripheral vasodilation at high altitudes-a field study. High Alt Med Biol 1:323-329

Elkington EJ (1968) Finger blood flow in Antarctica. J Physiol 199:1-10

Felicijan A, Golja P, Milcinski M, Cheung SS, Mekjavic IB (2008) Enhancement of cold-induced vasodilatation following acclimatization to altitude. Eur J Appl Physiol 104:201-206

Flouris AD, Westwood DA, Mekjavic IB, Cheung SS (2008) Effect of body temperature on cold induced vasodilation. Eur J Appl Physiol 104:491-499

Geurts CL, Sleivert GG, Cheung SS (2005) Local cold acclimation of the hand impairs thermal responses of the finger without improving hand neuromuscular function. Acta Physiol Scand 183:117-124

Geurts CL, Sleivert GG, Cheung SS (2006) Central and peripheral factors in thermal, neuromuscular, and perceptual adaptation of the hand to repeated cold exposures. Appl Physiol Nutr Metab $31: 110-117$

Imray CH, Richards P, Greeves J, Castellani JW (2011) Nonfreezing cold-induced injuries. BMJ Mil Health 157:79-84

Karliner JS, Sarnquist FF, Graber DJ, Peters RM Jr, West JB (1985) The electrocardiogram at extreme altitude: experience on Mt. Everest Am Heart J 109:505-513

Keramidas ME, Kolegard R, Eiken O (2018) In Shackleton's trails: central and local thermoadaptive modifications to cold and hypoxia after a man-hauling expedition on the Antarctic Plateau. J Therm Biol 73:80-90

Keramidas ME, Kolegard R, Mekjavic IB, Eiken O (2015) Hand temperature responses to local cooling after a 10-day confinement to normobaric hypoxia with and without exercise. Scand J Med Sci Sports 25:650-660

Krog J, Folkow B, Fox RH, Andersen KL (1960) Hand circulation in the cold of Lapps and North Norwegian fisherman. J Appl Physiol 15:654-658

Lewis T (1930) Observations upon the reactions of the vessels of the human skin to cold. Heart 15:177-208

Liu L, Breitner S, Pan X, Franck U, Leitte AM, Wiedensohler A, von Klot S, Wichmann HE, Peters A, Schneider A (2011) Associations between air temperature and cardio-respiratory mortality in the urban area of Beijing, China: a time-series analysis. Environ Health 10:51
Livingstone SD (1976) Changes in cold-induced vasodilation during Arctic exercises. J Appl Physiol 40:455-457

Mathew L, Purkayastha SS, Selvamurthy W, Malhotra MS (1977) Cold-induced vasodilatation and peripheral blood flow under local cold stress in man at altitude. Aviat Space Environ Med 48:497-500

Mekjavic IB, Dobnikar U, Kounalakis SN (2013) Cold-induced vasodilatation response in the fingers at 4 different water temperatures. Appl Physiol Nutr Metab 38:14-20

Mekjavic IB, Dobnikar U, Kounalakis SN, Musizza B, Cheung SS (2008) The trainability and contralateral response of cold-induced vasodilatation in the fingers following repeated cold exposure. Eur J Appl Physiol 104:193-199

Miller LK, Irving L (1962) Local reactions to air cooling in an Eskimo population. J Appl Physiol 17:449-455

Naidu M, Sachdeva U (1993) Effect of local cooling on skin temperature and blood flow of men in Antarctica. Int J Biometeorol $37: 218-221$

Nelms JD, Soper DJ (1962) Cold vasodilatation and cold acclimatization in the hands of British fish filleters. J Appl Physiol 17:444-448

O'Brien C, Castellani JW, Muza SR (2015) Acute hypobaric hypoxia effects on finger temperature during and after local cold exposure. High Alt Med Biol 16:244-250

Payne S, Macintosh A, Stock J (2018) The influence of digit size and proportions on dexterity during cold exposure. Am J Phys Anthropol 166:875-883

Purkayastha SS, Selvamurthy W, Ilavazhagan G (1992) Peripheral vascular response to local cold stress of tropical men during sojourn in the Arctic cold region. Jpn J Physiol 42:877-889

Rintämäki H, Hassi J, Smolander J, Louhevaara V, Rissanen S, Oksa J, Laapio H (1993) Responses to whole body and finger cooling before and after an Antarctic expedition. Eur J Appl Physiol Occup Physiol 67:380-384

Sendowski I, Savourey G, Besnard Y, Bittel J (1997) Cold induced vasodilatation and cardiovascular responses in humans during cold water immersion of various upper limb areas. Eur J Appl Physiol Occup Physiol 75:471-477

Tyler CJ, Reeve T, Cheung SS (2015) Cold-induced vasodilation during single digit immersion in 0 degrees $\mathrm{C}$ and 8 degrees $\mathrm{C}$ water in men and women. PLoS ONE 10:e0122592

Ward M (1974) Frostbite. Br Med J 1:67-70

West JB (2001) Acute mountain sickness at the South pole? High Alt Med Biol 2:559

West JB, Lahiri S, Maret KH, Peters RM Jr, Pizzo CJ (1983) Barometric pressures at extreme altitudes on Mt. Everest: physiological significance. J Appl Physiol Respir Environ Exerc Physiol 54:1188-1194

Wyndham CH, Plotkin R, Munro A (1964) Physiological reactions to cold of men in the Antarctic. J Appl Physiol 19:593-597

Young AJ, Sawka MN, Epstein Y, Decristofano B, Pandolf KB (1987) Cooling different body surfaces during upper and lower body exercise. J Appl Physiol 63:1218-1223

Publisher's Note Springer Nature remains neutral with regard to jurisdictional claims in published maps and institutional affiliations. 